\title{
Simple Nutritional and Inflammatory Markers Associated with Bed Sores in Elderly Stroke People
}

\author{
Mohammed Zein Abdulwadood, Safaa Hussein Ali* \\ Geriatrics and Gerontology Department, Faculty of Medicine, Ain Shams University, Cairo, Egypt \\ Email: "bokabokloz@yahoo.com
}

Received 14 February 2016; accepted 20 March 2016; published 23 March 2016

Copyright $@ 2016$ by authors and Scientific Research Publishing Inc.

This work is licensed under the Creative Commons Attribution International License (CC BY). http://creativecommons.org/licenses/by/4.0/

(c) (7) Open Access

\section{Abstract}

Background: Bed sores are major burden to hospital care and usually associated with worse prognosis and longer hospital stay. Aims: To evaluate whether simple biochemical inflammatory and nutritional markers would differ between those with bedsores and those without in elderly stroke patients and if there is a distinction between recent bed sore stroke patients and old bed sore stroke patients as regard these biomarkers. Methods: 80 Stroke elderly patients were enrolled and divided into four groups: patients with recent stroke who developed bedsores, patients with recent stroke who did not develop bedsores, patients with old stroke who developed bedsores and patients with old stroke who did not develop bedsores. Nutritional markers (albumin, total protein, magnesium, iron, total iron binding capacity (TIBC), hemoglobin and cholesterol) and inflammatory markers (total leucocyte count, neutrophil to lymphocyte ratio and ferritin) were compared between the four groups. Results: Concerning nutritional markers, albumin $(P=<$ $0.001)$, Alb/Pr ratio $(P=<0.001)$, TIBC $(P=<0.001)$ and cholesterol $(P=0.005)$ are lower in the acute stroke with bed sore patients versus acute stroke without bed sore. Lower albumin $(P=<$ 0.001 ) is only found in comparison between chronic stroke with bed sore patients and chronic without bed sore patients. There is a difference between acute stroke with bed sore and chronic stroke with bed sore concerning albumin $(P=<0.001)$, TIBC $(P=<0.001)$ and TG $(p=<0.001)$. Albumin is lower while TG and TIBC are higher in those with acute stroke with bed sores. Regarding inflammatory markers, high neutrophil and ferritin $(p=<0.001)$ were found in acute stroke with bed sore patients versus acute stroke without bed sore. No difference was found between chronic stroke with bed sore patients and chronic stroke without bed sore patients. Acute stroke with bed sore group has higher TLC, neutrophil, neut/lymph ratio and ferritin $(p=<0.001)$ than chronic stroke with bed sore group. Conclusions: Acute stroke patients with bed sores are the highest group as regard inflammatory markers due to acute stroke and bed sores together. The presence of bed sore itself causes or is caused by decrease in nutritional markers especially albumin in both, acute

\footnotetext{
"Corresponding author.
} 
and chronic strokes. Other markers are more evident in acute stroke patients who develop bed sore like higher ferritin and neutrophils and lower TIBC, alb/prot ratio and cholesterol. TG differs only in relation to acute stroke but not bed sore. MG was not different between the four groups.

\title{
Keywords
}

\author{
Bedsores, Nutritional, Inflammatory, Stroke, Elderly
}

\section{Introduction}

A pressure ulcer, also known as a pressure sore, decubitus ulcer or bedsore, is defined as an area of localized damage to the skin and underlying tissue caused by pressure, shear, friction and or a combination of these [1]. Applied pressure affects cellular metabolism by decreasing or obliterating tissue circulation, resulting in insufficient blood flow to the skin and underlying tissues, causing tissue ischaemia. Elderly patients with decreased mobility, limited mental status and increased skin friction and shear may have a higher risk of developing a pressure ulcer [2].

The prevalence of PU ranges from $6.6 \%$ to $46.6 \%$ for patients in hospitals or nursing homes, and more than $30 \%$ of PUs are full-thickness PUs [3].

It is well recognized that pressure ulcers represent a significant cause of morbidity and indeed mortality in elderly patients. These are particularly likely to develop in patients who are malnourished or have inflammatory conditions. The prevention of pressure ulcers involves a number of strategies designed to address both extrinsic factors, e.g. reducing the pressure duration or magnitude at the skin surface by repositioning or using pressure relieving cushions or mattresses; and intrinsic factors e.g. the ability of the patient's skin to remain intact and resist pressure damage by optimising hydration, circulation and nutrition. There is some evidence that malnutrition is positively correlated with pressure ulcer incidence and severity [4] [5]. Decreased calorie intake, dehydration, and a drop in serum albumin may decrease the tolerance of skin and underlying tissue to pressure, friction and shearing force, increasing risk of skin breakdown and reducing wound healing [6]. Serum albumin is commonly used as a measure of the amount of protein in the blood for healing. The combination of low energy and low protein intake is often described as protein-calorie or protein-energy malnutrition. The Prinz (prevalence and incidence) study which collected data from more than 45,000 patients in Austria between 1995 and 1999, showed that malnutrition—defined as a serum albumin less than $3.5 \mathrm{~g} / \mathrm{dl}$ —had been identified as a risk factor in $25 \%$ of patients [7]. A few studies suggest a correlation between protein-calorie malnutrition and pressure ulcers, too [8] [9]. The effectiveness of special diets in preventing and treating pressure ulcers has not yet been examined sufficiently, although many risk assessment tools [10] include nutritional status. Nevertheless, there is a consensus that nutrition is an important factor, evidenced by its incorporation in various guidelines, e.g. the EPUAP Pressure Ulcer Prevention Guidelines [1] [11]. Because undernutrition may influence clinical outcomes, it is important to assess nutritional status and treat undernutrition particularly during acute stage of stroke.

In a previous study, Scivoletto et al., 2004 analyzed spinal cord injury with pressure sores before and after surgical intervention for ulcer healing and compared with matched SCI patients without sores and with patients with pressure sores and other diseases They demonstrated that patients with pressure sores often showed the coexistence of anaemia (with increased ferritin values and reduced transferrin), serum protein alteration (hypoalbuminemia with inverse albumin/globulin ratio, increased level of globulins and total hypoproteinemia) and inflammatory status (high erythrocyte sedimentation rate (ESR) and C-reactive protein (CRP) and white cell counts) [12]. Some researchers suggested that these alterations might be due to a chronic inflammatory status produced by the pressure sores and might be similar to chronic inflammatory diseases (such as rheumatoid arthritis) and tumors [13].

To our knowledge, the former study was the only one to study nutritional and inflammatory markers, however, in Spinal cord injury (SCI) patients. In addition, previous studies did not describe whether nutritional and inflammatory markers could be affected by the stroke duration. The advantage of comparing nutritional and inflammatory markers in acute versus old bed sore stroke remains unclear. Also we chose to use simple markers which was available every day and everywhere. Therefore, assessment of the risk of bed sores can be accessible. 
The purpose of this study was to evaluate whether simple biochemical inflammatory and nutritional markers would differ between those with bedsores and those without in elderly stroke patients and if there was a distinction between recent bed sore stroke patients and old bed sore stroke patients as regard these biomarkers.

\section{Methodology}

\subsection{Ethics}

This study had the approval of the ethics committee of the Ain Shams Faculty of medicine. All subjects consented (orally or written) to participation in the study

\subsection{Study Design}

Case control study

\subsection{Patient Selection}

Eighty elderly patients were enrolled. Acute stroke from the in-patient ward, of the Geriatric department, AinShams University Hospital. Neoplastic pathologies, chronic inflammatory and infectious diseases, collagenopathies, pre-existing anaemias and osteomyelitis were ruled out. Patients who received blood transfusions before and/or after surgical intervention were excluded. They were divided into four groups:

\section{Group I:}

Twenty stroke elderly patients who developed bedsore within two weeks of the stroke event (recent stroke with bedsores).

\section{Group II:}

Twenty stroke elderly patients who did not develop bedsore within two weeks of the stroke event (recent stroke without bedsores).

\section{Group III:}

Twenty stroke elderly patients who developed bedsore within six months of the stroke event (old stroke with bedsores).

\section{Group IV:}

Twenty stroke elderly patients who did not develop bedsore within six months of the stroke event (old stroke without bedsores).

\subsection{Data Collection}

At admission, each patient gave his or her informed consent and then Extensive demographic and clinical data were also collected at that time. Patients' baseline characteristics, including age, gender, and marital statuses were collected. Laboratory data included Nutritional markers (albumin, total protein, magnesium, iron, hemoglobin and cholesterol) and acute phase reactants (total leucocyte count, neutrophil to lymphocyte ratio and ferritin). As a visceral protein compartment, serum albumin level has been used for nutritional assessment and is known to be a good predictor of clinical outcome [14]. However, serum albumin level is of limited utility in detecting acute nutritional changes owing to its long half-life (18 days) as stated by Lipkin et al., 1993 [15]. We therefore also measured transferrin levels, which have shorter half-lives (8 days).

\subsection{Assessment of Bedsore Risk}

We used Braden scale to assess the risk of bed sores. The Braden Scale for Predicting Pressure Sore Risk was developed by Barbara Braden and Nancy Bergstrom. The Braden Scale for Predicting Pressure Sore Risk is a clinically validated tool that allows nurses and other health care providers to reliably score a patient's level of risk for developing pressure ulcers [16]. It measures functional capabilities of the patient that contribute to either higher intensity and duration of pressure or lower tissue tolerance for pressure. Lower levels of functioning indicate higher levels of risk for pressure ulcer development.

\section{Description}

The Braden Scale is a summated rating scale made up of six subscales scored from 1 - 4 (1 for low level of functioning and 4 for the highest level or no impairment). Total scores range from 6 - 23 (one subscale is scored 
with values of 1 - 3, only). The subscales measure functional capabilities of the patient that contribute to either higher intensity and duration of pressure, or lower tissue tolerance for pressure. A lower Braden Scale Score indicates lower levels of functioning and, therefore, higher levels of risk for pressure ulcer development.

At risk (Braden score 15 - 18).

Moderate risk (Braden score 13 - 14).

High risk (Braden score 10 - 12).

Very high risk (Braden score $=9$ ).

\subsection{Statistical Methods}

The collected data were coded, tabulated, and statistically analyzed using IBM SPSS statistics (Statistical Package for Social Sciences) software version 22.0, IBM Corp., Chicago, USA, 2013. Descriptive statistics were done for quantitative data as mean \pm SD (standard deviation) and minimum\& maximum of the range for quantitative parametric data, while it was done for qualitative data as number and percentage. Inferential analyses were done for quantitative variables using independent t-test in cases of two independent groups with parametric data. In qualitative data, inferential analyses for independent variables were done using Chi square test for differences between proportions. The level of significance was taken at $P$ value $<0.05$ is significant, otherwise is non-significant.

\section{Results}

\subsection{Demographic Data}

The demographic and clinical characteristics (mean \pm standard deviation) of the studied groups are reported in Table 1. Acute stroke with pressure sores seems to be significantly older in relation to acute stroke without PU $(P=<0.001)$. On the contrary, the chronic stroke cases without PU are older $(P=<0.001)$. No difference as regard gender distribution between the four groups $(P=0.614)$. Braden scale is significantly lower in acute stroke with bed sore in comparison to other groups $(P<0.001)$.

\subsection{Nutritional Markers}

Table 2 shows that there is difference between acute stroke with bed sore patients and acute stroke without bed sore as regard albumin $(P=<0.001)$, Albumin/ protein ratio (Alb/Pr) ratio $(P=<0.001)$, TIBC $(P=<0.001)$ and cholesterol $(P=0.005)$. All are lower in the acute stroke with bed sore patients (Figure 1 and Figure 2).

Table 1. Comparison between study groups regarding age, sex and Barden score.

\begin{tabular}{|c|c|c|c|c|c|c|}
\hline Variables & Measures & Group A $(N=20)$ & Group B $(N=20)$ & Group C $(\mathrm{N}=20)$ & Group D $(\mathrm{N}=20)$ & $\mathrm{P}$ \\
\hline \multirow{3}{*}{$\begin{array}{c}\text { Age } \\
\text { (years) }\end{array}$} & Mean \pm SD & $74.9 \pm 10.5$ & $64.9 \pm 12.3$ & $69.5 \pm 7.3$ & $77.9 \pm 10.2$ & \multirow{3}{*}{$\hat{\mathbf{0 . 0 0 1}}^{\wedge}$} \\
\hline & Range & $70.0-79.8$ & $59.1-70.6$ & $66.1-72.9$ & 73.1 - 82.6 & \\
\hline & HG & b, c & a & $\mathrm{a}, \mathrm{b}$ & C & \\
\hline \multirow{3}{*}{ Sex } & Male & $13(65.0 \%)$ & $10(50.0 \%)$ & $10(50.0 \%)$ & $9(45.0 \%)$ & \multirow{3}{*}{$\begin{array}{c}\& \\
0.614\end{array}$} \\
\hline & Female & 7 (35.0\%) & 10 (50.0\%) & $10(50.0 \%)$ & 11 (55.0\%) & \\
\hline & HG & $\mathrm{a}$ & a & A & A & \\
\hline \multirow{3}{*}{ Braden } & Mean \pm SD & $9.2 \pm 2.2$ & $11.7 \pm 3.4$ & $12.4 \pm 1.7$ & $12.7 \pm 1.0$ & \multirow{3}{*}{$\stackrel{\wedge}{<0.001}$} \\
\hline & Range & $8.1-10.2$ & $10.1-13.3$ & $11.6-13.2$ & $12.2-13.1$ & \\
\hline & HG & $\mathrm{a}$ & $\mathrm{b}$ & B & B & \\
\hline \multirow{5}{*}{ Braden } & At Risk & $0(0.0 \%)$ & $4(20.0 \%)$ & $2(10.0 \%)$ & $1(5.0 \%)$ & \multirow{5}{*}{$<0.001^{*}$} \\
\hline & Moderate & $2(10.0 \%)$ & $2(10.0 \%)$ & $6(30.0 \%)$ & $7(35.0 \%)$ & \\
\hline & High & $6(30.0 \%)$ & $9(45.0 \%)$ & $11(55.0 \%)$ & $12(60.0 \%)$ & \\
\hline & V. High & $12(60.0 \%)$ & $5(25.0 \%)$ & $1(5.0 \%)$ & $0(0.0 \%)$ & \\
\hline & HG & a & a, b & b, c & C & \\
\hline
\end{tabular}

$\wedge$ ANOVA test with post hoc Tukey-B, \& Chi square test with post hoc Chi square tests. \$Fisher Exact test with post hoc Fisher Exact tests. * Significant. 


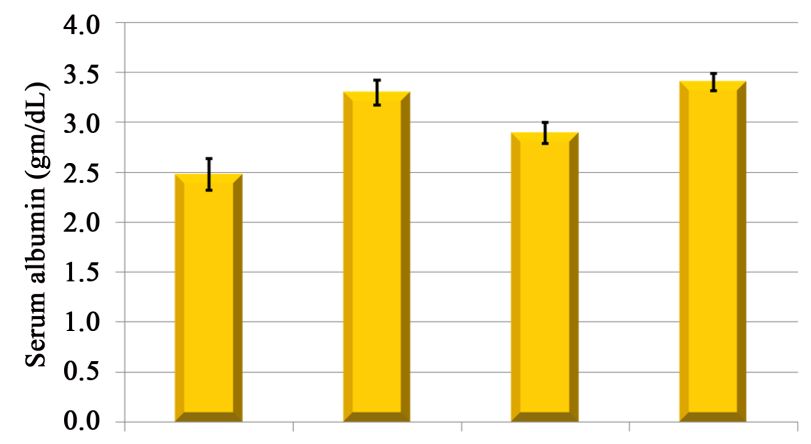

Sores-Early No sores-Early Sores-Late No sores-Late

Figure 1. Serum albumin in the four groups shows that albumin is significantly different between group 1 versus 2 , group 3 versus 4 and group 1 versus 3 .

Table 2. Comparison between study groups regarding nutritional markers.

\begin{tabular}{|c|c|c|c|c|c|c|}
\hline Variables & Measures & Group A $(N=20)$ & Group B $(N=20)$ & Group C $(\mathrm{N}=20)$ & Group D $(N=20)$ & $\mathbf{P}$ \\
\hline \multirow{3}{*}{$\underset{\mathbf{m g} / \mathbf{d L}}{\mathbf{A l b}}$} & Mean \pm SD & $2.5 \pm 0.7$ & $3.3 \pm 0.5$ & $2.9 \pm 0.5$ & $3.4 \pm 0.4$ & \\
\hline & Range & $2.1-2.8$ & $3.0-3.6$ & $2.7-3.1$ & $3.2-3.6$ & $\hat{\imath}^{\wedge}{ }^{*}{ }^{*}$ \\
\hline & HG & $\mathrm{a}$ & c & $\mathrm{b}$ & $\mathrm{C}$ & \\
\hline \multirow{3}{*}{$\underset{\text { mg/dL }}{\operatorname{Pr}}$} & Mean \pm SD & $5.8 \pm 1.3$ & $6.3 \pm 0.9$ & $6.1 \pm 0.6$ & $6.6 \pm 0.6$ & \\
\hline & Range & $5.1-6.4$ & $5.8-6.8$ & $5.8-6.3$ & $6.3-6.9$ & $\hat{\wedge} \hat{0.032}^{*}$ \\
\hline & HG & $\mathrm{a}$ & $\mathrm{a}, \mathrm{c}$ & $\mathrm{a}, \mathrm{c}$ & $\mathrm{C}$ & \\
\hline \multirow{3}{*}{ Alb/Pr } & Mean \pm SD & $0.43 \pm 0.09$ & $0.52 \pm 0.06$ & $0.48 \pm 0.06$ & $0.52 \pm 0.05$ & \\
\hline & Range & $0.39-0.48$ & $0.49-0.56$ & $0.45-0.50$ & $0.49-0.54$ & $\hat{\imath}^{\wedge}{ }^{*}$ \\
\hline & HG & $\mathrm{a}$ & $\mathrm{b}$ & a, b & B & \\
\hline \multirow{3}{*}{$\begin{array}{l}\text { HB } \\
\text { g/dL }\end{array}$} & Mean \pm SD & $11.2 \pm 2.9$ & $12.2 \pm 3.2$ & $10.6 \pm 1.7$ & $12.0 \pm 1.5$ & \\
\hline & Range & $9.8-12.5$ & $10.7-13.7$ & 9.8 - 11.4 & $11.3-12.7$ & 0.155 \\
\hline & HG & $\mathrm{a}$ & $\mathrm{a}$ & $\mathrm{a}$ & A & \\
\hline \multirow{3}{*}{$\underset{\mathbf{m g} / \mathbf{d L}}{\mathbf{M g}}$} & Mean \pm SD & $2.0 \pm 0.7$ & $2.0 \pm 0.4$ & $2.1 \pm 0.2$ & $2.0 \pm 0.3$ & \\
\hline & Range & $1.7-2.4$ & $1.8-2.2$ & $2.0-2.2$ & $1.9-2.1$ & $\hat{\wedge} \hat{0.013}^{*}$ \\
\hline & HG & a & A & a & A & \\
\hline \multirow{3}{*}{$\begin{array}{l}\text { Chol } \\
\text { mg/dL }\end{array}$} & Mean \pm SD & $129.3 \pm 33.7$ & $178.8 \pm 53.1$ & $135.2 \pm 45.1$ & $158.3 \pm 31.9$ & \\
\hline & Range & $107.8-150.7$ & $152.4-205.2$ & $114.1-156.3$ & $143.4-173.3$ & $\stackrel{\wedge}{0.005^{*}}$ \\
\hline & HG & a & B & a & $\mathrm{a}, \mathrm{b}$ & \\
\hline \multirow{3}{*}{$\underset{\mathrm{mg} / \mathrm{dL}}{\mathrm{TG}}$} & Mean \pm SD & $129.5 \pm 56.1$ & $132.3 \pm 72.1$ & $57.4 \pm 29.1$ & $49.5 \pm 16.7$ & \\
\hline & Range & $93.9-165.1$ & 96.4 - 168.1 & 43.8 - 71.0 & $41.7-57.3$ & $\stackrel{\wedge}{<0.001^{*}}$ \\
\hline & HG & $\mathrm{a}$ & A & $\mathrm{b}$ & B & \\
\hline \multirow{3}{*}{$\begin{array}{l}\text { TIBC } \\
\mu \mathrm{g} / \mathrm{dL}\end{array}$} & Mean \pm SD & $90.1 \pm 66.2$ & $188.6 \pm 87.6$ & $31.7 \pm 8.7$ & $42.3 \pm 30.1$ & \\
\hline & Range & $42.7-137.5$ & 79.8 - 297.4 & $27.3-36.0$ & $28.2-56.4$ & $\hat{\imath}^{\wedge}{ }^{*}{ }^{*}$ \\
\hline & HG & A & $\mathrm{b}$ & c & $\mathrm{C}$ & \\
\hline
\end{tabular}

$\wedge$ ANOVA test with post hoc Tukey-B, ${ }^{*}$ Significant. Alb = albumin, $\mathrm{Pr}=$ total protein, Alb/Pr = Albumin/protein ratio, HB = hemoglobin, $\mathrm{MG}=$ magnesium, $\mathrm{Chol}=$ cholesterol, $\mathrm{TG}=$ triglycerides, $\mathrm{TIBC}=$ total iron binding capacity. 


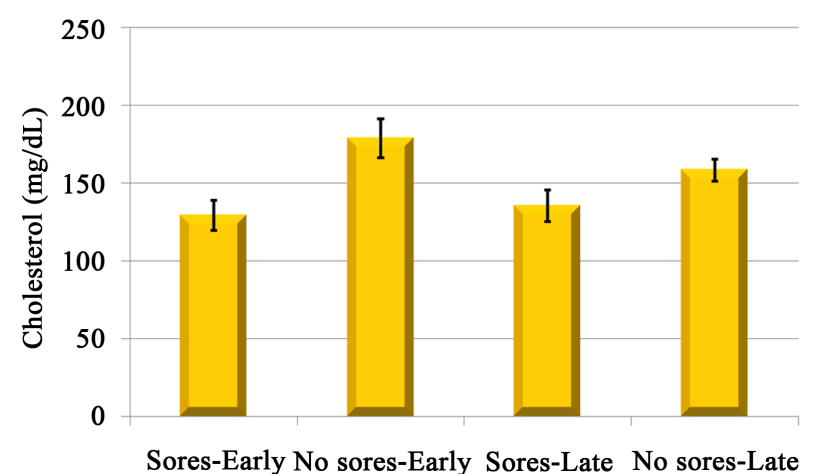

Figure 2. Cholesterol level in different groups shows that cholesterol $(P=0.005)$ is lower in the acute stroke with bed sore patients versus acute stroke without bed sore.

There is difference between chronic stroke with bed sore patients and chronic without bed sore patients regarding albumin $(P=<0.001)$ only where albumin is lower in those with bed sores.

Results revealed difference between acute stroke with bed sore and chronic stroke with bed sore concerning albumin $(P=<0.001)$, TIBC $(P=<0.001)$ and triglycerides (TG) $(p=<0.001)$. Albumin is lower while TG and TIBC are higher in those with acute stroke with bed sores (Figure 3 ).

Results showed no difference between acute stroke without bed sore and chronic stroke without bed sore except for TIBC $(P=<0.001)$ as regard nutritional markers measured.

Hemoglobin (HB) and magnesium (MG) was not different statistically between groups although lower in first group.

\subsection{Inflammatory Markers}

Table 3 shows that there is difference between acute stroke with bed sore patients and acute stroke without bed sore as regard neutrophil and ferritin. Both are higher significantly in the first group $(P=<0.001)$ (Figure 4 and Figure 5).

There is no difference between chronic stroke with bed sore patients and chronic without bed sore patients regarding inflammatory markers

Results revealed difference between acute stroke with bed sore and chronic stroke with bed sore concerning total leucocyte count (TLC), neutrophil, neut/lymph ratio and ferritin. All are higher significantly in the first group $(P=<0.001)$.

Results showed difference between acute stroke without bed sore and chronic stroke without bed sore as regard neutrophil and neut/lymph ratio $(P=<0.001)$.

Results revealed difference between acute stroke with bed sore and chronic stroke with bed sore concerning albumin $(P=<0.001)$, TIBC $(P=<0.001)$ and triglycerides (TG) $(p=<0.001)$. Albumin is lower while TG and TIBC are higher in those with acute stroke with bed sores (Figure 3 ).

Results showed no difference between acute stroke without bed sore and chronic stroke without bed sore except for TIBC $(P=<0.001)$ as regard nutritional markers measured.

Hemoglobin (HB) and magnesium (MG) was not different statistically between groups although lower in first group.

\section{Discussion}

Pressure ulcers, though an ancient medical problem (found in autopsies on Egyptian mummies), still afflicts patients even up to the present day. The presence of a wound may increase metabolic demands due to the metabolic response to injury. In addition, large quantities of protein can be lost in wound exudates each day [17]. One of the most important risk factors for bed sores is malnutrition. Although malnutrition is common in medical, [18], geriatric, [19] and stroke [20], patients, its treatment has received little attention. Because undernutrition may influence clinical outcomes, it is important to assess nutritional status and treat under nutrition particularly during acute stage of stroke. 


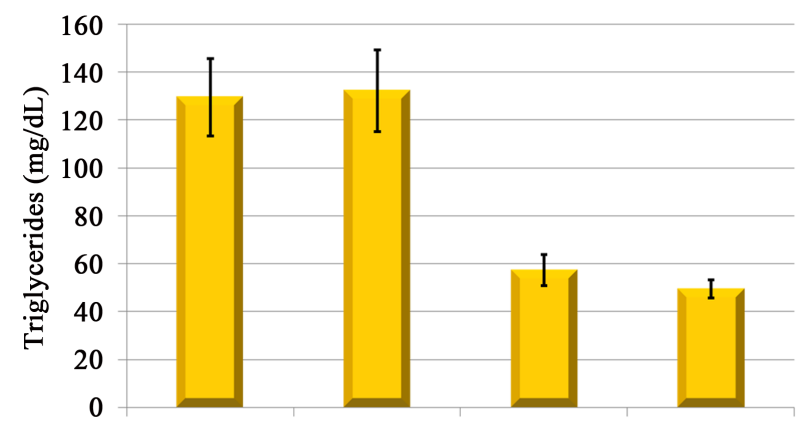

Sores-Early No sores-Early Sores-Late No sores-Late

Figure 3. Triglyceride level in different groups shows that TG is higher in those with acute stroke with bed sores versus and chronic stroke with bed sore $(p=<0.001)$.

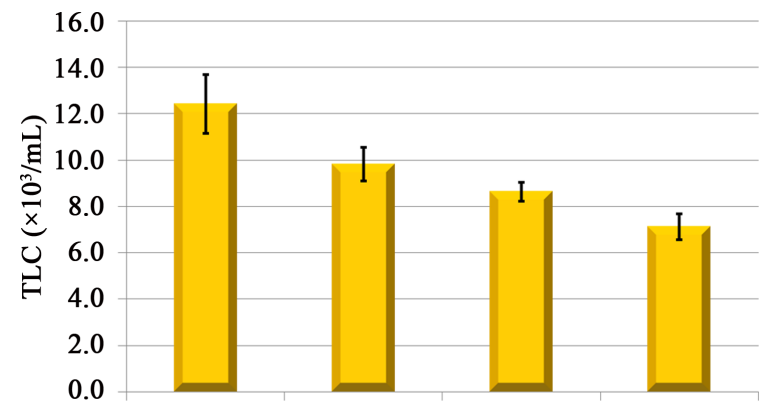

Sores-EarlyNo sores-Early Sores-Late No sores-Late

Figure 4. Total leucocyte count in different groups. Shows that Acute stroke with bed sore have higher TLC $(P=<0.001)$ than chronic stroke with bed sore.

Table 3. Comparison between study groups regarding inflammatory markers.

\begin{tabular}{|c|c|c|c|c|c|c|}
\hline Variables & Measures & Group A $(N=20)$ & Group B $(N=20)$ & Group C $(N=20)$ & Group D $(N=20)$ & $\mathbf{P}$ \\
\hline \multirow{3}{*}{$\begin{array}{l}\text { TLC } \times \\
10^{3} / \mu L\end{array}$} & Mean \pm SD & $12.4 \pm 5.7$ & $9.8 \pm 3.2$ & $8.6 \pm 1.9$ & $7.1 \pm 2.4$ & \\
\hline & Range & $9.8-15.1$ & $8.3-11.3$ & $7.8-9.5$ & $6.0-8.3$ & $\hat{<} \hat{0.001}^{*}$ \\
\hline & HG & a & a, b & B & B & \\
\hline \multirow{3}{*}{$\begin{array}{l}\text { Neutro } \\
\text { cells/pL }\end{array}$} & Mean \pm SD & $10.2 \pm 5.4$ & $7.2 \pm 3.3$ & $5.9 \pm 1.7$ & $4.1 \pm 1.8$ & \\
\hline & Range & $7.6-12.7$ & $5.6-8.9$ & $5.1-6.7$ & $3.2-4.9$ & $\hat{\wedge}$ \\
\hline & HG & a & B & b, c & $\mathrm{C}$ & \\
\hline \multirow{3}{*}{$\begin{array}{c}\text { Neut/ } \\
\text { Lymph }\end{array}$} & Mean \pm SD & $9.3 \pm 7.1$ & $7.3 \pm 6.9$ & $3.5 \pm 2.1$ & $2.0 \pm 0.9$ & \\
\hline & Range & $6.0-12.7$ & $3.9-10.7$ & $2.6-4.5$ & $1.6-2.5$ & $\hat{<0.001}^{*}$ \\
\hline & HG & $\mathrm{a}$ & A & B & B & \\
\hline \multirow{3}{*}{$\begin{array}{c}\text { Ferritin } \\
\mathrm{ng} / \mathrm{mL}\end{array}$} & Mean \pm SD & $426.8 \pm 152.9$ & $198.4 \pm 99.8$ & $130.7 \pm 107.3$ & $186.9 \pm 102.0$ & \\
\hline & Range & 298.9 - 554.6 & 74.5 - 322.3 & $79.0-182.5$ & $139.2-234.7$ & $\stackrel{\wedge}{<0.001^{*}}$ \\
\hline & HG & a & B & $\mathrm{b}$ & B & \\
\hline
\end{tabular}

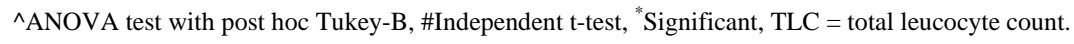




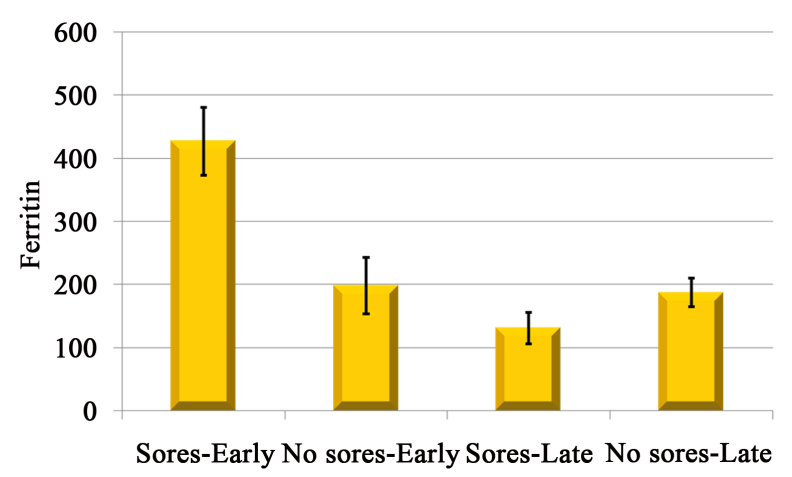

Figure 5. Ferritin in different groups shows that Acute stroke with bed sore have higher ferritin $(P=<0.001)$ than chronic stroke with bed sore. Also in acute stroke with bed sore patients versus acute stroke without bed sore $(P=<0.001)$.

This is the first study to our knowledge comparing acute and chronic stroke as regard simple inflammatory and nutritional markers and relationship to bedsore emergence.

The current study compared acute stoke with bed sores and acute stroke without bed sore. As regard inflammatory markers, it is found that both neutrophil and ferritin are higher significantly in the acute stroke with bed sore patients versus acute stroke without bed sore $(p=<0.001)$. Regarding nutritional markers, there is difference as regard albumin $(P=<0.001)$, Alb/Pr ratio $(P=<0.001)$, TIBC $(P=<0.001)$ and cholesterol $(P=0.005)$. All are lower in the acute stroke with bed sore patients. Hb and MG are not different between group 1 and 2 . The differences here are mostly due to/caused by bed sores as both groups are acute stroke. Less evident changes was found between group $3 \& 4$ (chronic stroke groups). We compared chronic stroke with bed sore patients and chronic without bed sore patients. No difference was found regarding inflammatory markers. For nutritional markers, Results revealed There is difference regarding albumin $(P=<0.001)$ where albumin is lower in those with bed sores which support our hypothesis that inflammatory markers are caused by acute stroke rather than bed sores. Albumin has a big share, not only as a nutritional marker, but also as an inflammatory marker in both cases of bed sores (acute and chronic strokes).

Idowu et al., 2011 evaluate the associated risk factors for pressure ulceration in traumatic spinal cord injured [21]. There was significant association between low serum albumin at the time of admission and the incidence of pressure sores $(P=0.037)$.

The association between the incidence of pressure sore and low serum proteins indicate that dysmetabolism may be contributory to the aetiology of pressure ulceration. However, some evidence suggests that this may be an effect rather than the cause of the ulcer. There is no doubt that ulcer healing and immunity against wound infections is greatly dependent on the nutritional status of the individual patient. Furthermore, serum albumin has been reported as a cost-effective measure of nutritional status. That this relatively simple and affordable test is underutilized has also been highlighted by previous studies among in-hospital patients [22]. The utilization of prognostic indicators such as serum albumin in early detection of adverse outcome may reduce the incidence of complications.

Hong et al., 2008 found that acute ischemic stroke Patients with medical complications (including sores) had older age, lower baseline hemoglobin and albumin levels, and higher baseline glucose and white blood cell counts which agrees with our results [23].

Gurcay et al., 2009 evaluated serum markers in traumatic spinal cord injured (SCI) patients, with and without pressure sores. Similar to our study, the patients with pressure sores showed anemia with reduced TIBC, and increased ferritin. They also had increased WBC and reduced lymphocytes, total protein and albumin. Statistically significant correlations were found between $\mathrm{Hb}$, Htc, lymphocytes, WBC, and serum protein levels, and grade of pressure sores [24].

Likewise, Scivoletto et al., studied Spinal cord injury patients with pressure sores before and after surgical intervention for ulcer healing and compared with matched SCI patients without sores and with patients with pressure sores and other diseases. Mean pressure sore duration 3.7 months. They found that compared to the control group, the patients with pressure sores showed anaemia with reduced serum iron, increased ferritin and reduced transferrin and transferrin saturation. They also had increased ESR and CRP, total hypoproteinemia, hypoalbuminemia, and reduced albumin/globulin ratio [12].

The advantages of transferrin over albumin levels in detecting undernutrition was demonstrated in this study in 
acute cases apparently than chronic cases in differentiating presence of bed sore or not. Moreover, whereas other studies have used anthropometric parameters, such as caliper skin fold measures at multiple body sites, for nutritional assessment, we did not use these parameters, as they have been shown to be unsuitable for stroke patients with tetraparesis or spasticity as a sequelae of stroke, especially in assessing acute nutritional change as stated by Lipkin and his colleagues, 1993 [15].

To reveal if duration of stroke affect inflammatory and nutritional markers in association to bed sore, we compared group $1 \& 3$ (acute stoke with bed sores and chronic stoke with bed sores). regarding inflammatory markers, We discovered that TLC, neutrophil, neut/lymph ratio and ferritin are higher significantly in the acute stroke with bed sore patients versus chronic stoke with bed sores $(p=<0.001)$. when we compared acute stroke without bed sore and chronic stroke without bed sore, there is difference as regard neutrophil and neut/lymph ratio ( $P=<0.001$ ). These differences can only points to acute stroke as a culprit for this difference. This was evidenced by Chakraborty et al., 2013. They found ferritin were consistently higher among patients with acute ischemic stroke and concluded that ferritin and low levels of albumin are associated with increased severity and poorer long term prognosis of stroke [25].

Concerning total leucocyte count, Grau et al., 1994 showed that leukocytosis influence prognosis after stroke [26]. It has been suggested that leukocyte activation may occur as a consequence of infection preceding onset of stroke (Reith et al., 1996), [27] or as a consequence brain damage (Hallenbeck, 1996) [28]. A similar finding in two Egyptian study found that hyperglycemia and leukocytosis were considered as bad prognostic factors for both short-term and long-term ischemic stroke outcome (Hashem et al., 2004) [29]. Likewise Mostafa et al., 2015 studied patients with first attack of noncardioembolic ischemic stroke and divided into two groups: 40 patients with favorable outcome were included in the first group and 20 patients with bad outcome in the second group [30]. TLC was higher in bad outcome group. Nardi et al. 2012 found that an elevated leukocyte count in the acute phase of cerebral ischemia is a significant independent predictor of poor initial-stroke severity, poor clinical outcome after $72 \mathrm{~h}$, and discharge disability [31].

Despite that, it is clear that the process of inflammation is an important component in the pathogenesis of ischemic stroke. The differences in results between studies could be attributed to different factors. The differences in the study design (some of these studies followed the case control design whereas others were crosssectional comparative studies), the differences in sample sizes, and the different ways of assessment of ischemic stroke severity and outcome may be responsible for these contradictory results. There is a need for more studies to evaluate the use of the inflammatory markers as predictors of outcome in different types of ischemic stroke.

As per nutritional markers, Results revealed difference between acute stroke with bed sore and chronic stroke with bed sore concerning albumin $(P=<0.001)$, TIBC $(P=<0.001)$ and TG $(P=<0.001)$. Albumin is lower while TG, TIBC are higher in those with acute stroke with bed sores. As regard those without bed sores, Results showed acute stroke without bed sore and chronic stroke without bed sore only differ as regard TIBC and TG both are higher in acute stroke $(P=<0.001)$.

As stated before, Chakraborty et al., 2013concluded that ferritin and low levels of albumin are associated with increased severity and poorer long term prognosis of stroke [25]. Yuan et al., 2015 found that TG is higher in ischemic stroke patients in relation to healthy control [32]. We did not find a study searched TIBC in acute stoke but The HUNT study found that being in the highest quartile of transferrin saturation is risky for Mortality from ischemic heart disease (Mørkedal et al., 2011) [33].

The current study has several limitations. First, it was conducted in a single tertiary hospital, thus limiting generalization of our results to other communities or countries where dietary patterns are likely different. Second, it was difficult to recruit acute stroke developing bedsore within two weeks. The low incidence of poststroke bedsore may have resulted in small sample size.

\section{Conclusion}

In conclusion, this study shows that acute stroke patients with bed sores are the highest group as regard inflammatory markers due to acute stroke and bed sores together. The presence of bed sore itself causes or is caused by decrease in nutritional markers especially albumin in both, acute and chronic strokes. Other markers are more evident in acute stroke patients who develop bed sore like higher ferritin and neutrophils and lower TIBC, alb/prot ratio and cholesterol. TG differs only as regard presence of acute stroke but not bed sore. MG was not different between the four groups. Undernutrition independently predicts bed sore emergence in stroke patients. Strategic nutritional support, particularly in patients with acute stroke, may improve clinical outcomes after stroke. 


\section{Acknowledgements}

We acknowledge the study participants for their gracious help.

\section{Competing Interests}

No conflict of interest has been declared by the authors.

\section{Disclosure Statement}

This paper was supported by Ain Shams University, geriatric department. All authors declare that there is no financial support or relationship that may pose conflicts of interest.

\section{Authors Contribution}

Mohammed Zein Abdulwadood-designed the study, collected the data, analyzed the data, drafted the manuscript \& reviewed the manuscript.

Safaa Hussein Ali-designed the study, collected the data, drafted the manuscript \& reviewed the manuscript.

\section{References}

[1] Bergstrom, N, Braden, B., Laguzza, A. and Holman, A. (1987) The Braden Scale for Predicting Pressure Sore Risk. Nursing Research, 36, 205-210. http://dx.doi.org/10.1097/00006199-198707000-00002

[2] Bergstrom, N., Braden, M.J., Laguzza, A. and Holman, V. (1992) A Prospective Study of Pressure Sore Risk among Institutionalized Elderly. Journal of the American Geriatrics Society, 40, 747-758. http://dx.doi.org/10.1111/j.1532-5415.1992.tb01845.x

[3] Berlowitz, D.R. and Wilking, S.V. (1989) Risk Factors for Pressure Sores. A Comparison of Cross-Sectional and Cohort-Derived Data. Journal of the American Geriatrics Society, 37, 1043-1050. http://dx.doi.org/10.1111/j.1532-5415.1989.tb06918.x

[4] Bistrian, B.R., Blackburn, G.L., Vitale, J., Cochran, D. and Naylor, J. (1976) Prevalence of Malnutrition in General Medical Patients. Journal of the American Medical Association, 235, 1567-1570. http://dx.doi.org/10.1001/jama.1976.03260410023017

[5] Braden, B.J. and Bergstrom, N. (1994) Predictive Validity of the Braden Scale for Pressure Sore Risk in a Nursing Home Population. Research Nursing Health, 17, 459-470. http://dx.doi.org/10.1002/nur.4770170609

[6] Chakraborty, B., Vishnoi, G., Goswami, B., Gowda, S.H., Chowdhury, D. and Agarwal, S. (2013) Lipoprotein(a), Ferritin, and Albumin in Acute Phase Reaction Predicts Severity and Mortality of Acute Ischemic Stroke in North Indian Patients. Journal of Stroke and Cerebrovascular Diseases, 22, e159-e167. http://dx.doi.org/10.1016/j.jstrokecerebrovasdis.2012.10.013

[7] EPUAP 1998, European Pressure Ulcer Advisory Panel Guideline (EPUAP) (1998) A Policy Statement on the Prevention of Pressure Ulcers from the European Pressure Ulcer Advisory Panel. British Journal of Nursing, 7, 888-890. http://dx.doi.org/10.12968/bjon.1998.7.15.17016

[8] EPUAP (2003) European Pressure Ulcer Advisory Panel. Pressure. Ulcer Treatment Guidelines. http://www.epuap.org/gltreatment.html

[9] Fife, C., Otto, G., Capsuto, E.G., Brandt, K., Lyssy, K., Murphy, K., et al. (2001) Incidence of Pressure Ulcers in a Neurologic Intensive Care Unit. Critical Care Medicine, 29, 283-290. http://dx.doi.org/10.1097/00003246-200102000-00011

[10] Finucane, T.E. (1995) Malnutrition, Tube Feeding and Pressure Sores. Journal of the American Geriatrics Society, 43, 447-451. http://dx.doi.org/10.1111/j.1532-5415.1995.tb05822.x

[11] Fuoco, U., Scivoletto, G., Pace, A., Vona, V.U. and Castellano, V. (1997) Anemia and Serum Protein Alteration in Patients with Decubitus Ulcer. Spinal Cord, 35, 58-60. http://dx.doi.org/10.1038/sj.sc.3100340

[12] Gariballa, S.E., Parker, S.G., Taub, N. and Castleden, C.M. (1998) Influence of Nutritional Status on Clinical Outcome after Acute Stroke. The American Journal of Clinical Nutrition, 68, 275-281.

[13] Grau, A.J., Sigmund, R. and Hacke, W. (1994) Modification of Platelet Aggregation by Leukocytes in Acute Ischemic Stroke. Stroke, 25, 2149-2152. http://dx.doi.org/10.1161/01.STR.25.11.2149

[14] Gurcay, E., Bal, A., Gurcay, A.G. and Cakci, A. (2009) Evaluation of Blood and Serum Markers in Spinal Cord Injured Patients with Pressure Sores. Saudi Medical Journal, 30, 413-417. 
[15] Hallenbeck, J.M. (1996) Significance of the Inflammatory Response in Brain Ischemia. Acta Neurochirurgica Supplement, 66, 27-31. http://dx.doi.org/10.1007/978-3-7091-9465-2_5

[16] Hashem, S., Fathy, H., El-Sayed, M., Hassan, R., Samir, H. and Kamal, M. (2004) Outcome and Prognosis after Ischemic Strokes. The Egyptian Journal of Neurology, Psychiatry and Neurosurgery, 41, 195-212.

[17] Hong, K.S., Kang, D.W., Koo, J.S., Yu, K.H., Han, M.K., Cho, Y.J., Park, J.M., Bae, H.J. and Lee, B.C. (2008) Impact of Neurological and Medical Complications on 3-Month Outcomes in Acute Ischaemic Stroke. European Journal of Neurology, 15, 1324-1331. http://dx.doi.org/10.1111/j.1468-1331.2008.02310.x

[18] Idowu, O.K., Yinusa, W., Gbadegesin, S.A. and Adebule, G.T. (2011) Risk Factors for Pressure Ulceration in a Resource Constrained Spinal Injury Service. Spinal Cord, 49, 643-647. http://dx.doi.org/10.1038/sc.2010.175

[19] Keelaghan, E., Margolis, D., Zhan, M. and Baumgarten, M. (2008) Prevalence of Pressure Ulcers on Hospital Admission among Nursing Home Residents Transferred to the Hospital. Wound Repair and Regeneration, 16, 331-336. http://dx.doi.org/10.1111/j.1524-475X.2008.00373.x

[20] Lipkin, E.W. and Bell, S. (1993) Assessment of Nutritional Status: The Clinician's Perspective. Clinics in Laboratory Medicine, 13, 329-352.

[21] Mørkedal, B., Laugsand, L.E., Romundstad, P.R. and Vatten, L.J. (2011) Mortality from Ischaemic Heart Disease: Sex-Specific Effects of Transferrin Saturation, Serum Iron, and Total Iron Binding Capacity. The HUNT Study. European Journal of Preventive Cardiology, 18, 687-694. http://dx.doi.org/10.1111/j.1524-475X.2008.00373.x

[22] Mostafa, M.A., Mohamed, K., Elewa, M.K. and Mohamed, N.A. (2015) Admission Leukocytosis, C-Reactive Protein and Erythrocyte Sedimentation Rate in Acute Noncardioembolic Cerebral Ischemia: Influence on Early Outcome. The Egyptian Journal of Neurology, Psychiatry and Neurosurgery, 52, 223-227.

[23] Mueller, S.D., Hoerist, K. and Bahnsen, B. (2001) Prophylaxis and Therapy of Decubitus Ulcers-Importance of Nutritional Medicine. Caregiver + Altenpflegerin, 1, 14. http://www.diet-aachen.de

[24] Nardi, K., Milia, P., Eusebi, P., Paciaroni, M., Caso, V. and Agnelli, G. (2012) Admission Leukocytosis in Acute Cerebral Ischemia: Influence on Early Outcome. Journal of Stroke and Cerebrovascular Diseases, 21, 819-824. http://dx.doi.org/10.1016/j.jstrokecerebrovasdis.2011.04.015

[25] Perneger, T.V., Rae, A.C., Gaspoz, J.M., Borst, F., Vitek, O. and Heliot, C. (2002) Screening for Pressure Ulcer Risk in an Acute Care Hospital: Development of a Brief Bedside Scale. Journal of Clinical Epidemiology, 55, 498-505. http://dx.doi.org/10.1016/S0895-4356(01)00514-5

[26] Potter, J., Klipstein, K., Reilly, J.J. and Roberts, M. (1995) The Nutritional Status and Clinical Course of Acute Admissions to a Geriatric Unit. Age and Ageing, 24, 131-136. http://dx.doi.org/10.1093/ageing/24.2.131

[27] Reith, J., Jørgensen, H.S., Pedersen, P.M., Nakayama, H., Raaschou, H.O., Jeppesen, L.L. and Olsen, T.S. (1996) Body Temperature in Acute Stroke: Relation to Stroke Severity, Infarct Size, Mortality, and Outcome. Lancet, 347, 422-425. http://dx.doi.org/10.1016/S0140-6736(96)90008-2

[28] Russell, L. (2001) The Importance of Patients' Nutritional Status in Wound Healing. British Journal of Nursing, 10, S42-S49. http://dx.doi.org/10.12968/bjon.2001.10.sup1.5336

[29] Scivoletto, G., Fuoco, U., Morganti, B., Cosentino, E. and Molinari, M. (2004) Pressure Sores and Blood and Serum Dysmetabolism in Spinal Cord Injury Patients. Spinal Cord, 42, 473-476. http://dx.doi.org/10.1038/sj.sc.3101622

[30] Strauss, E.A. and Margolis, D.J. (1996) Malnutrition in Patients with Pressure Ulcers: Morbidity, Mortality, and Clinically Practical Assessments. Advances in Wound Care, 9, 37-40.

[31] Van Steelandt, T. (2000) Haeufigkeit und Kosten von Dekubitalgeschwueren-Prinz-Dekubituss studie. http://www.connect.co.at/kci/html/prinz.htm

[32] Westergren, A., Karlsson, S., Andersson, P., Ohlsson, O. and Hallberg, I.R. (2001) Eating Difficulties, Need for Assisted Eating, Nutritional Status and Pressure Ulcers in Patients Admitted for Stroke Rehabilitation. Journal of Clinical Nursing, 10, 257-269. http://dx.doi.org/10.1046/j.1365-2702.2001.00479.X

[33] Yuan, B.B., Luo, G.G., Gao, J.X., Qiao, J., Yang, J.B., Huo, K., Li, Y.B. and Liu, Y. (2015) Variance of Serum Lipid Levels in Stroke Subtypes. Clinical Laboratory, 61, 1509-1514. 


\section{Abbreviations}

Albumin/protein

C-reactive protein

Erythrocyte sedimentation rate

Hemoglobin

Magnesium

Pressure ulcer

Spinal cord injury

Total iron binding capacity

Total leucocyte count

Triglycerides

White blood cells
$\mathrm{Alb} / \mathrm{Pr}$

CRP

ESR

HB

MG

PU

SCI

TIBC

TLC

TG

WBC 